\title{
Plakofuranolactone as a Quorum Quenching Agent from the Indonesian Sponge Plakortis cf. lita
}

\author{
Valeria Costantino ${ }^{1, *}$, Gerardo Della Sala ${ }^{1}$, Kumar Saurav ${ }^{2}$, Roberta Teta ${ }^{1}$, Rinat Bar-Shalom ${ }^{2}$, \\ Alfonso Mangoni ${ }^{1}$ and Laura Steindler ${ }^{2}$ \\ 1 The Blue Chemistry Lab Group, Department of Pharmacy, University of Naples Federico II, 80131 Napoli, \\ Italy; gerardo.dellasala@unina.it (G.D.S.); roberta.teta@unina.it (R.T.); alfonso.mangoni@unina.it (A.M.) \\ 2 Department of Marine Biology, Leon H. Charney School of Marine Sciences, University of Haifa, \\ Mt. Carmel, 31905 Haifa, Israel; sauravverma17@gmail.com (K.S.); rbar-shal@univ.haifa.ac.il (R.B.-S.); \\ lsteindler@univ.haifa.ac.il (L.S.) \\ * Correspondence: valeria.costantino@unina.it; Tel.: +39-081-678-504
}

Academic Editor: Leticia V. Costa-Lotufo

Received: 10 October 2016; Accepted: 22 February 2017; Published: 28 February 2017

\begin{abstract}
There is an urgent need for novel strategies to fight drug resistance and multi-drug resistance. As an alternative to the classic antibiotic therapy, attenuation of the bacteria virulence affecting their Quorum sensing (QS) system is a promising approach. Quorum sensing (QS) is a genetic regulation system that allows bacteria to communicate with each other and coordinate group behaviors. A new $\gamma$-lactone that is capable of inhibiting the LasI/R QS system, plakofuranolactone (1), was discovered in the extract of the marine sponge Plakortis cf. lita, and its structure, including absolute configuration, was determined by NMR spectroscopy, MS spectrometry, and quantum-mechanical prediction of optical rotation. The quorum quenching activity of plakofuranolactone was evaluated using reporter gene assays for long- and short-chain signals (E. coli pSB1075, E. coli pSB401, and C. violeaceum CV026) and was confirmed by measuring the total protease activity (a virulence factor which is under control of the LasI/R system) of the wild-type P. aeruginosa PAO1. Further research will be pursued to assess the potential of plakofuranolactone as a new antivirulence lead compound and a chemical tool to increase the knowledge in this field.
\end{abstract}

Keywords: antibacterial from marine sponges; antivirulence lead compounds; quorum sensing system; plakofuranolactone; quorum quenching activity; marine sponges; Plakortis lita; Pseudomonas aeruginosa; reporter gene assays

\section{Introduction}

The problem of antibiotic resistance, strictly connected to the large overuse of antibiotics in clinical practice and animal husbandry, is rising as a global emergency. There is an urgent need for new drugs to be used as therapeutic agents aimed at virulence factors rather than killing the pathogen, thus providing less selective pressure for evolution of resistance particularly among gram-negative bacteria. It has been reported that half the deaths associated with clinical infection in Europe are associated with multi-drug-resistant bacteria (the so-called "superbugs") [1]. According to the Infection Disease Society of America (IDSA), the incidence of antibiotic resistance is rapidly increasing. At the same time, fewer new antibiotics are being developed. New compounds that target a variety of virulence factors can serve as adjunctive therapy and potentiate the effect of existing antibiotics. Novel scaffolds in drug discovery are inspired by natural products (NPs) and, although plants remain the major source, marine organisms have been shown to be a treasure of novel lead compounds for drug research [2-6]. Among others, sponges and associated bacteria are potential rich sources of antibacterial compounds $[7,8]$. 
A recent pharmacological approach to control infections relies on studies performed on quorum sensing (QS), a mechanism of cell-cell communication and gene regulation in bacteria. QS acts using chemically different signal molecules, also called autoinducers. Among others, acylated homoserine lactones (AHLs, Figure 1) are used by many Gram-negative bacteria. At low cell density, bacteria produce and release low levels of AHLs, whilst at higher densities, the chemical signals accumulate and once they reach a critical level (quorum) they interact with receptor proteins (LuxR homologs) [9], and induce expression of specific genes, often including those for AHL synthesis (luxI homolog). In many pathogens, QS controls the expression of virulence factors, and thus blocking QS will preclude the pathogen from producing those mediators and exotoxins, among others, that accomplish the infection process in the host. One of the best studied models is the opportunistic pathogen Pseudomonas aeruginosa, where two AHL-QS systems are organized hierarchically with the RhlI/R system subordinate to the LasI/R one $[10,11]$. The two QS circuits regulate a range of virulence factors [12,13], that assist P. aeruginosa in both acute and chronic infections, mostly in immune-compromised patients [14]. Because QS regulates virulence in pathogens like P. aeruginosa, interference with QS (quorum quenching, QQ) has been proposed as a potential therapeutic strategy for fighting pathogens by attenuating the virulence effectors that are regulated by QS [15]. QQ potential was detected in marine sponges and sponge isolates $[16,17]$ and therefore sponges appear as an attractive target to identify novel anti-virulence and QS-inhibiting lead molecules. One means of QS-inactivation is to block the QS signal receptors (e.g., LasR in P. aeruginosa) with the antagonist capable of penetrating the bacterial cell, and blocking the cascade of production of virulence factors.<smiles>[R]C([X])CC(=O)NC1CCOC1=O</smiles>

Figure 1. General structure of acyl homoserine lactones (AHLs). $\mathrm{R}$ is typically a saturated or monounsaturated $\mathrm{C}_{1}$ through $\mathrm{C}_{11}$ alkyl chain; $\mathrm{X}$ is typically $-\mathrm{H},-\mathrm{OH}$, or $=\mathrm{O}$.

In a search for molecules active on the QS system, structural analogs of AHLs are obvious candidates. For example, the marine-derived $\gamma$-lactones isolated from the red alga Delisea pulchra that mimic the lactone moiety of AHLs, have been shown to inhibit AHL-mediated gene expression [18]. Marine sponges of the genus Plakortis are a promising source of novel bioactive lactones. The $\delta$-lactone simplactones (e.g., 2, Figure 2) were isolated in 1999 by Cafieri et al. [19] from a Caribbean specimen of Plakortis simplex, the $\alpha$-methylene- $\gamma$-lactone plakolide A (3) was isolated by Guanasakera et al. from a Caribbean Plakortis sp. [20], and the $\gamma$-lactone methyl ester 4 was isolated in 1990 by De Guzman and Schimtz [21] from a specimen of Plakortis lita collected in the Pacific Ocean.<smiles>COC(=O)CC1OC(=O)CC1C</smiles>

1<smiles>C=C1C[C@](C)(/C=C/C=C/[IH+]c2ccccc2)OC1=O</smiles>

3<smiles>CC[C@H]1COC(=O)C[C@H]1O</smiles>

2<smiles>COC(=O)C[C@@H]1C=CC(=O)O1</smiles>

4

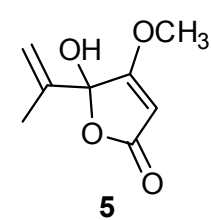

Figure 2. Structures of plakofuranolactone (1), three lactones isolated from marine sponges of the genus Plakortis (2-4), and of penicillic acid (5). 
An Indonesian specimen of Plakortis cf. lita, from which we had previously obtained the hopanoid derivative plakohopanoid [22], was available in our laboratory. Re-examination of the extract of this sponge in the search of novel lactones active as QS inhibitors led to the isolation of the new lactone plakofuranolactone (1). In this paper, we report the structural elucidation of the lactone $\mathbf{1}$ and the evaluation of its QQ activity by in vitro assays.

\section{Results and Discussion}

\subsection{Isolation and Structural Elucidation of Plakofuranolactone (1)}

An in-depth re-examination of the organic extract of the Indonesian sponge Plakortis cf. lita was made in the search for novel bioactive lactones. Fraction A2 from the organic extract of the sponge (for extraction/fractionating procedures see ref. [22]) was purified by reversed-phase HPLC on an RP-18 column, followed by normal-phase $\mathrm{HPLC}$ on a $\mathrm{SiO}_{2}$ column, to yield $1.3 \mathrm{mg}$ of plakofuranolactone (1).

The high-resolution ESI mass spectrum of compound 1 showed a pseudomolecular ion peak at $m / z 173.0798\left([\mathrm{M}+\mathrm{H}]^{+}\right)$indicating the molecular formula $\mathrm{C}_{8} \mathrm{H}_{12} \mathrm{O}_{4}$ (calcd. $m / z$ 173.0808). The presence of two ester carbonyl signals as the sole $s p^{2}$ carbon signals in the ${ }^{13} \mathrm{C}$ NMR spectrum, together with the three unsaturations indicated by the molecular formula, suggested a cyclic structure. Analysis of the ${ }^{1} \mathrm{H}$ NMR and COSY (COrrelation SpectroscopY) spectra (see Table 1) showed the presence in compound 1 of a $-\mathrm{CH}_{2}-\mathrm{CH}(\mathrm{O}-)-\mathrm{CH}\left(\mathrm{CH}_{3}\right)-\mathrm{CH}_{2}-$ part structure $(\mathrm{C}-2$ through $\mathrm{C}-5, \mathrm{C}-7)$ and an O-methyl group $\left(\mathrm{H}_{3}-8\right.$, singlet at $\left.\delta 3.71\right)$. The HMBC (Heteronuclear Multiple Bond Correlation) correlation of $\mathrm{H}_{2}-2(\delta 2.71)$ and $\mathrm{H}_{3}-8$ with $\mathrm{C}-1$ ( $\delta$ 172.2) defined the presence of a methoxycarbonyl group at C-2, while the HMBC correlations of $\mathrm{H}-5 \mathrm{a}(\delta 2.79), \mathrm{H}-5 \mathrm{~b}(\delta 2.24)$, and H-3 $(\delta 4.96)$ with C-6 ( $\delta$ 178.7) were indicative of a $\gamma$-lactone. The concomitant presence of two strong NOESY (Nuclear Overhauser Effect Spectroscopy) correlation peaks between $\mathrm{H}_{3}-7$ and $\mathrm{H}_{2}-2$ and between $\mathrm{H}-3$ and $\mathrm{H}-4$ was indicative of the cis relationship of the two substituents on the $\gamma$-lactone ring.

Table 1. NMR data of plakofuranolactone (1) (700 MHz, $\left.\mathrm{CD}_{3} \mathrm{OD}\right)$.

\begin{tabular}{|c|c|c|c|c|c|}
\hline Pos. & & $\delta_{\mathrm{H}}[$ mult., $J(\mathrm{~Hz})]$ & $\delta_{C}[$ mult. $]$ & COSY & НМВС \\
\hline 1 & & & $172.2(\mathrm{C})$ & & \\
\hline 2 & & $2.71(\mathrm{~d}, 7.1)$ & $35.7\left(\mathrm{CH}_{2}\right)$ & 3,8 & $1,3,4$ \\
\hline 3 & & $4.96(q, 6.7)$ & $81.0(\mathrm{CH})$ & $2,4,5 \mathrm{a}$ & $1,2,4,5,6,7$ \\
\hline 4 & & $2.75(\mathrm{~m})$ & $33.8(\mathrm{CH})$ & $3,5 a, 5 b, 7$ & $5,6,7$ \\
\hline \multirow[t]{2}{*}{5} & $\mathrm{a}$ & $2.79(\mathrm{dd}, 16.9,8.0)$ & $37.5\left(\mathrm{CH}_{2}\right)$ & $3,4,5 b, 7$ & $3,4,6,7$ \\
\hline & $\mathrm{b}$ & $2.24(\mathrm{dd}, 16.9,4.4)$ & & $4,5 a, 7$ & $3,4,6,7$ \\
\hline 6 & & & $178.7(\mathrm{C})$ & & \\
\hline 7 & & $1.01(\mathrm{~d}, 7.1)$ & $14.0\left(\mathrm{CH}_{3}\right)$ & $4,5 \mathrm{a}, 5 \mathrm{~b}$ & $3,4,5$ \\
\hline 8 & & $3.71(\mathrm{~s})$ & $52.3\left(\mathrm{CH}_{3}\right)$ & 2 & 1 \\
\hline
\end{tabular}

The close structural similarity of compound 1 with the methyl ester 4 isolated from the same Plakortis species [21] suggested a common configuration at C-3, and thus the $(3 S, 4 S)$ absolute configuration for $\mathbf{1}$. While in the original report [23] assignment of the absolute configuration of compound 5 was based on its electronic circular dichroism (ECD) spectrum, this approach was not possible for compound 1, lacking the conjugated $\pi$ system. It has been recently shown [24] that quantum-mechanical calculation of optical rotation may be a reliable method to predict experimental optical rotations, provided that the conformational behavior of the molecule under investigation is properly considered. Therefore, we used this method to elucidate the absolute configuration of compound 1. Briefly (see the Experimental Section and Table S1 in Supplementary Materials for details), twelve conformers of $(3 S, 4 S)-1$ in an energy range of $4 \mathrm{kcal} / \mathrm{mol}$ were obtained from a 10 ps molecular dynamics simulation in the CVFF (Consistent Valence Force Field) force field. The geometry of each conformer was quantum-mechanically optimized using the program Gaussian 09 [25] at the CAM-B3LYP/AUG-cc-pVDZ level of theory. Optical rotation of each optimized conformer 
was then calculated using time-dependent density functional theory (TDDFT) at the same theory level. The Boltzmann-weighted mean of the optical rotations of the individual conformers provided a predicted value of -82.8 for the optical rotation of 1 , in excellent agreement with the experimental value of $[\alpha]_{\mathrm{D}}^{25}=-84$. Therefore, the structure of plakofuranolactone (1) was defined as 1-methyl (3S,4S)-3-hydroxy-4-methylhexanedioate 3,6-lactone.

\subsection{Determination of Non-Inhibitory Concentration (NIC)}

Plakofuranolactone (1) was evaluated for determination of its non-inhibitory concentration (NIC) against E. coli pSB401 (pSB401), E. coli pSB1075 (pSB1075), P. aeruginosa PAO1 (PAO1), and C. violaceum CV026 (CV026), the four strains used for testing quorum quenching activity. Determination of NIC is important to rule out any possible growth inhibition artifacts during quorum quenching assays. The growth-inhibitory activities of compound $\mathbf{1}$ and of the positive control $\mathbf{5}$ were tested at concentrations between $0.781 \mu \mathrm{M}$ and $800 \mu \mathrm{M}$. Compound 1 showed no inhibitory activity against CV026, pSB401, and pSB1075 at any tested concentration, and a dose dependent inhibition against PAO1 above $200 \mu \mathrm{M}$. No growth inhibition compared with the control (solvent only) was observed for both compounds and for all the strains at concentrations between $0.781 \mu \mathrm{M}$ and $200 \mu \mathrm{M}$ (Figure 3). In addition, the growth curve of the strains was determined in the presence of $200 \mu \mathrm{M}$ of compound $\mathbf{1}$, and no significant effect was found compared to the control (Figure S7). Therefore, this concentration was used for further evaluation of QQ activity.

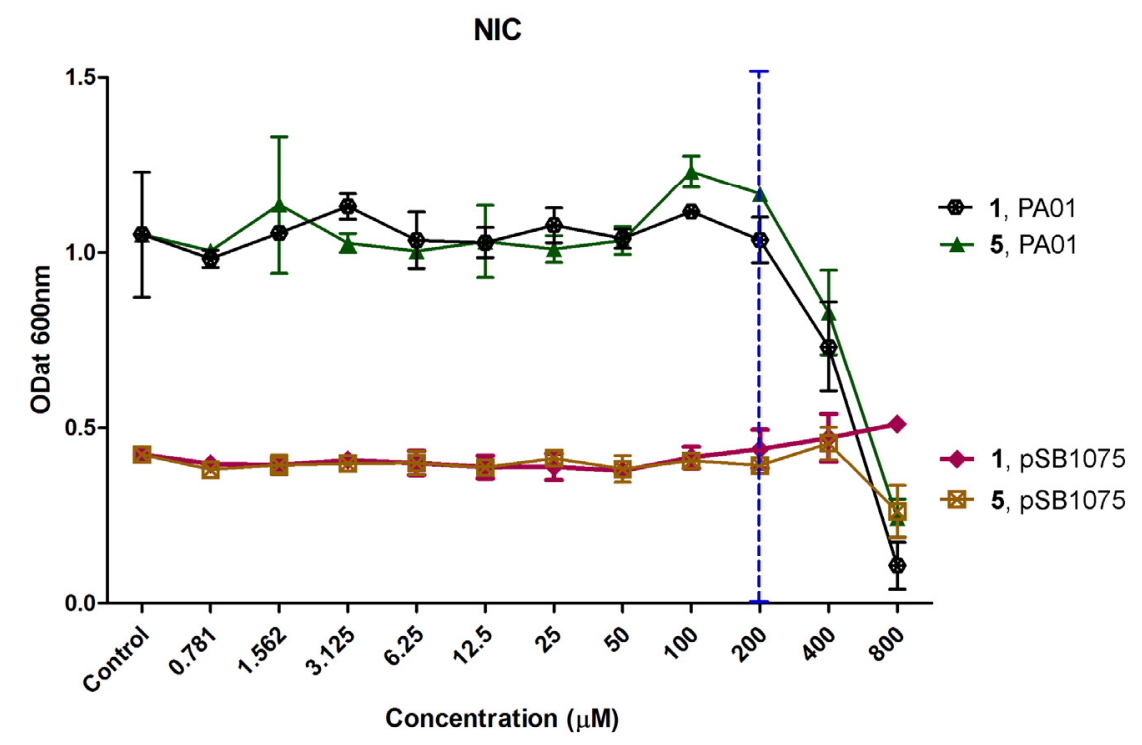

Figure 3. Dose dependent inhibition profile and determination of the non-inhibitory concentration (NIC) of plakofuranolactone (1) and penicillic acid (5) against Pseudomonas aeruginosa PAO1 and E. coli pSB1075. The control represents the growth of each tested organism grown in the presence of the diluting solvent used (methanol).

\subsection{Quorum Quenching Activity of Plakofuranolactone (1)}

Plakofuranolactone (1) shows some structural relationship with an AHL. More interestingly, it appears closely related with penicillic acid (5), a fungal metabolite which has been shown to inhibit the QS system of P. aeruginosa [26]. We hypothesized that this molecule may interfere with QS activity in P. aeruginosa as well, and tested this hypothesis with QS biosensors. Two biosensors, CV026 and pSB401, were used to determine its ability to affect QS systems based on short $\left(C_{4}-C_{8}\right)$ acyl side chain signals. It was found that $\mathbf{1}$ did not show any inhibitory activity against these biosensors (Figure $\mathrm{S} 8$ Supplementary Materials). QQ activity of plakofuranolactone (1) was further tested using a long chain $\left(C_{10}-C_{14}\right)$ acyl side chain based reporter assay with the QS biosensor pSB1075. In addition, the 
influence of compound $\mathbf{1}$ on the level of two QS-regulated extracellular virulence factors produced by wild-type Pseudomonas aeruginosa PAO1 was measured. The fungal metabolite penicillic acid $(P A, 5)$ was used as a positive control in all the experiments. It was shown that 5 exerts its QQ effect by destabilizing LuxR/LasR, thereby accelerating the proteolytic degradation of this QS regulator protein $[27,28]$.

\subsubsection{Dose Dependent Quantification of Bioluminescence for the QQ Assay and Specificity to} the LasI/LasR System

The reporter strains were used in the presence of the respective cognate AHL signaling molecules, and a decrease in bioluminescence in the presence of the test compound $\mathbf{1}$ or the control compound 5 was interpreted as QQ activity. Figure 4 shows normalized bioluminescence results for treated (1 and 5) reporter strain pSB401 (Figure 4A) and pSB1075 (Figure 4B), activated with their cognate signal molecules after $4 \mathrm{~h}$ of incubation.
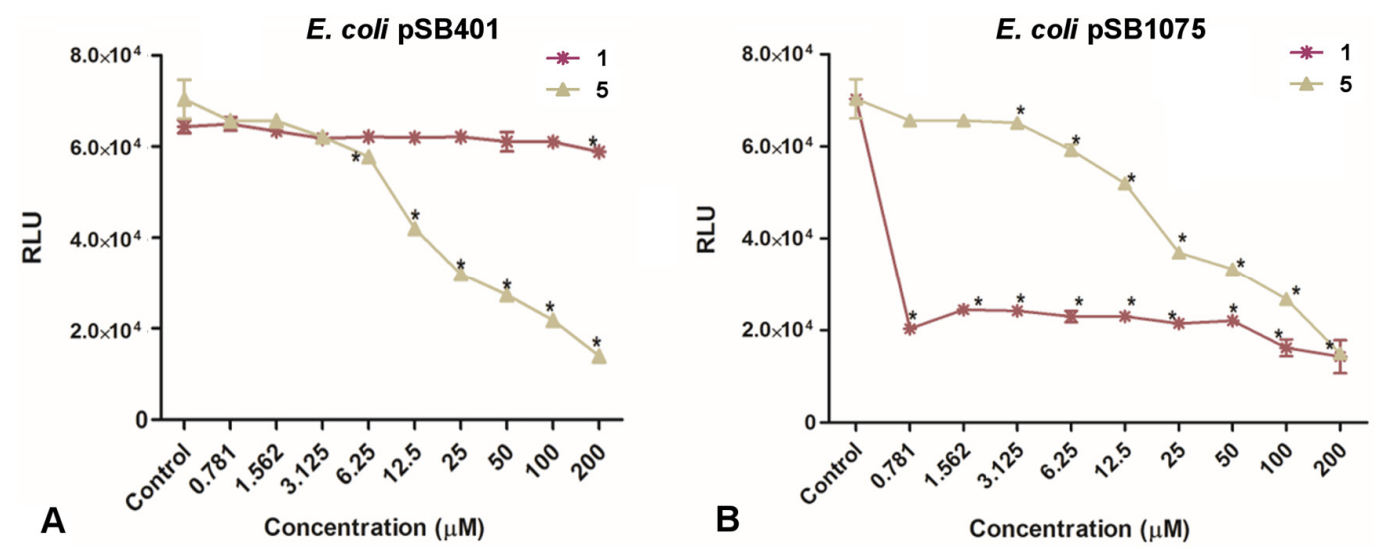

Figure 4. Dose dependent effect of plakofuranolactone (1) and penicillic acid (PA, 5) on the quorum sensing (QS) dependent bioluminescence of the LuxR-based reporter E. coli pSB401 induced by 3-oxo-C6-HSL (panel A) and the LasR-based reporter E. coli pSB1075 induced by 3-oxo-C12-HSL (Panel B). Data is expressed as SD of the mean $(n=2)$. Significance (according to Dunnett's test, $p<0.05$ ) is shown with an asterisk.

Compound 1 significantly inhibited the bioluminescence of pSB1075 at all concentrations tested $(0.781-200 \mu \mathrm{M})$ (ANOVA, Dunnett's test, $p<0.05$ ), while compound 5 showed a dose response for bioluminescence inhibition with $\mathrm{IC}_{50}$ at $25 \mu \mathrm{M}$ (ANOVA, Dunnett's test, $p<0.05$ ). In contrast, there was no inhibition of bioluminescence by pSB401 in the presence of compound 1 . Since both the reporter strains (pSB401 and pSB1075) harbor the same luciferase reporter system and only with the pSB1075 strain was the bioluminescence affected by compound $\mathbf{1}$, we suggest that there is no interference with the biochemistry of the bacterial luciferase, and rather compound $\mathbf{1}$ is specific in its inhibition of the lasR system. The pSB1075 biosensor has been previously used for isolation and identification of QQ lead molecules. An example is the isolation of 8-epi-malyngamide $C$, malyngamide $C$, malyngolide, and lyngbyoic acid from the extracts of $\mathrm{L}$. majuscula. 8-Epi-malyngamide $\mathrm{C}$ and malyngamide $\mathrm{C}$ reduced 3-oxo-C12-HSL induced bioluminescence at a concentration of $10 \mu \mathrm{M}$ [29]. Malyngolide was identified as a QS inhibitor with an EC50 value of $12.2 \pm 1.6 \mu \mathrm{M}$. This compound was also found to inhibit LasR regulated production of elastase by P. aeruginosa PAO1 with EC50 $=10.6 \pm 1.8 \mu \mathrm{M}[30]$. Lyngbyoic acid also antagonized 3-oxo-C12-HSL induced bioluminescence by pSB1075 with an $\mathrm{IC}_{50}$ of approximately $100 \mu \mathrm{M}$ and reduced pyocyanin and elastase production in P. aeruginosa [31]. Further work is required to reveal the mechanism of action by which compound $\mathbf{1}$ inhibits the Las-QS system. 


\subsubsection{Inhibition of Virulence Factor Production-Pyocyanin and Total Protease Activity}

To study the ability of plakofuranolactone (1) to down-regulate QS-regulated virulence factors of $P$. aeruginosa, the levels of two extracellular virulence factors were measured. Virulence factors examined included total protease activity, which is directly controlled by the LasI/R system, and pyocyanin production, which is mainly controlled by the RhlI/R system [32]. Pseudomonas aeruginosa PAO1, a wild type opportunistic pathogen strain, was used for these experiments. The activity of protease production was shown to be inhibited by compound $\mathbf{1}$ in a dose-dependent manner in PAO1. A similar dose dependent inhibitory effect was observed for compound 5 (positive control) (Figure 5A). Accordingly, compound 1 seems to exert its inhibition of protease activity through the inhibition of LasR, in a similar way as compound $\mathbf{5}$. However, whilst compound $\mathbf{5}$ showed also a dose dependent inhibition of pyocyanin production, compound 1 showed a weaker inhibition, and only at the highest concentrations tested. It is frequently found that small molecules targeting the LasR receptor show a remarkably lower $\mathrm{IC}_{50}$ in native P. aeruginosa than in E. coli reporters [33]. Several possible reasons have been proposed, and to some extent demonstrated, for this trend, the most important being the lower membrane permeability and enhanced active efflux in P. aeruginosa, and the different levels of receptor expression between P. aeruginosa (native levels) and E. coli (overexpressed receptor) [34].
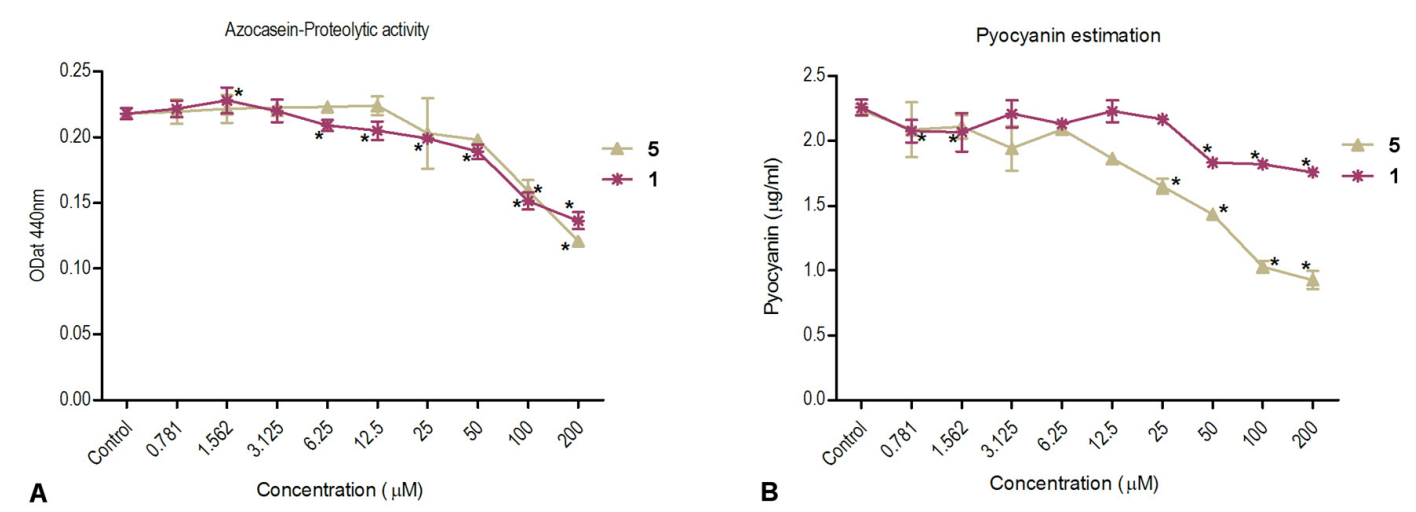

Figure 5. Dose dependent inhibition of proteolytic activity (panel A) and pyocyanin production (panel B) by plakofuranolactone (1) and penicillic acid (5). P. aeruginosa PAO1 grown in the presence of diluting solvent was used as a negative control in both experiments. Data is expressed as SD of the mean $(n=2)$. Significance (according to Dunnett's test, $p<0.05)$ is shown with an asterisk.

\section{Experimental Section}

\subsection{General Experimental Procedures}

High-resolution ESI-MS (ElectroSpray Ionization-Mass Spectrometry) and HR-ESI-HPLC (High Resolution-ElectroSpray Ionization-High Performance Liquid Chromatography) experiments were performed on a Thermo LTQ Orbitrap XL mass spectrometer coupled to a Thermo U3000 HPLC system (Thermo Fisher Scientific Spa, Rodano, Italy). The spectra were recorded by infusion into the ESI source using $\mathrm{MeOH}$ as the solvent. NMR spectra were determined on Varian Unity Inova spectrometers (Agilent Technologies, Cernusco sul Naviglio, Italy) at $700 \mathrm{MHz}$; chemical shifts were referenced to the residual solvent signal $\left(\mathrm{CD}_{3} \mathrm{OD}: \delta_{\mathrm{H}} 3.31, \delta_{\mathrm{C}} 49.30\right)$. For an accurate measurement of the coupling constants, the one-dimensional ${ }^{1} \mathrm{H}$ NMR spectra were transformed at $64-\mathrm{K}$ points (digital resolution: $0.09 \mathrm{~Hz}$ ). Homonuclear ${ }^{1} \mathrm{H}$ connectivities were determined by a COSY experiment. Through-space ${ }^{1} \mathrm{H}$ connectivities were evidenced using a NOESY experiment with a mixing time of $500 \mathrm{~ms}$. The HSQC spectra were optimized for ${ }^{1} J_{\mathrm{CH}}=142 \mathrm{~Hz}$ and the HMBC experiments for ${ }^{2,3} J_{\mathrm{CH}}=8.3 \mathrm{~Hz}$. High performance liquid chromatography (HPLC) was performed on a Varian Prostar 210 apparatus equipped with a Varian 350 refractive index detector (Agilent Technologies, Cernusco sul Naviglio, Italy). 


\subsection{Collection, Extraction, and Isolation}

A specimen of Plakortis cf. Lita (order Homosclerophorida, family Plakinidae) was collected in January 2008 along the coasts of the Bunaken Island in the Bunaken Marine Park of Manado. A voucher sample (No. MAN08-02) has been deposited at the Dipartimento di Farmacia, Università di Napoli Federico II. The sponge ( $380 \mathrm{~mL}$ of volume before extraction and $50 \mathrm{~g}$ of dry weight after extraction) was cut into pieces and extracted with $\mathrm{MeOH}(3 \times 1.5 \mathrm{~L}), \mathrm{MeOH} / \mathrm{CHCl}_{3}(4 \times 1.5 \mathrm{~L})$, and $\mathrm{CHCl}_{3}(2 \times 1.5 \mathrm{~L})$. The $\mathrm{MeOH}$ extracts were partitioned with $\mathrm{H}_{2} \mathrm{O}$ and $\mathrm{BuOH}$; the organic layer was added to the $\mathrm{CHCl}_{3}$ extracts, affording $8.16 \mathrm{~g}$ of dark brown oil, which was chromatographed on a column packed with RP-18 silica-gel. A fraction eluted with $\mathrm{H}_{2} \mathrm{O} / \mathrm{MeOH}(7: 3,270 \mathrm{mg})$ was chromatographed on a silica normal-phase column, thus giving a fraction (15.9 $\mathrm{mg}$ ) which was eluted with $100 \%$ AcOET and shown to contain compound 1 . This latter fraction was further subjected to normal-phase HPLC on a $\mathrm{SiO}_{2}$ column (Phenomenex, Torrance, CA, USA) [ $n$-Hex/AcOET (2:8), Luna Silica, $250 \times 4.6 \mathrm{~mm}, 5 \mu \mathrm{m}$ ], which gave $1.3 \mathrm{mg}$ of pure compound 1 .

Plakofuranolactone (1): Colorless amorphous solid, $[\alpha]_{\mathrm{D}}^{25}=-84(\mathrm{MeOH}) ; \mathrm{HRESIMS}$ (High Resolution-ElectroSpray Ionization-Mass Spectrometry) (positive ion mode, $\mathrm{MeOH}$ ) $\mathrm{m} / z$ 173.0798 $\left([\mathrm{M}+\mathrm{H}]^{+}, \mathrm{C}_{8} \mathrm{H}_{13} \mathrm{O}_{4}{ }^{+} \text {gives 173.0808), } m / z \text { 195.0616 ([M + Na }\right]^{+}, \mathrm{C}_{8} \mathrm{H}_{12} \mathrm{O}_{4} \mathrm{Na}^{+}$gives 195.0628); ${ }^{1} \mathrm{H}-$ and ${ }^{13} \mathrm{C}-\mathrm{NMR}$ : Table 1.

\subsection{Quantum Mechanical Calculation of the Optical Rotation of Plakofuranolactone (1)}

A conformational search for $\mathbf{1}$ was performed using molecular dynamics (MD) (Insight II/Discover package [35] and CVFF force field). The MD simulation was performed at $300 \mathrm{~K}$ for $10 \mathrm{~ns}$, and the coordinates produced by the simulation were saved every 50 ps, producing 200 structures. Each structure saved from MD was then minimized. The calculation revealed twelve conformers (all within $4 \mathrm{kcal} / \mathrm{mol}$ from the lowest energy conformer), differing for the puckering of the five-membered lactone ring and/or for the conformation of the methoxycarbonylmethyl group. Geometry optimizations of each conformer from MD was performed using density functional theory (DFT) with the Gaussian 09 program [25], the CAM-B3LYP functional, the AUG-cc-pVDZ basis set, and the IEF-PCM model for the solvent, $\mathrm{MeOH}$; the results of vibrational frequency analysis confirmed that all conformers were in a true energy minimum, and were used to obtain their free energies. The optical rotation of each DFT-optimized conformer was then calculated using TDDFT at the same theory level (the results are reported in Table S1, Supplementary Materials). Finally, the weighted mean of individual optical rotations was calculated based on DFT relative free energies and Boltzmann statistics $(T=298 \mathrm{~K})$.

\subsection{Determination of Non-Inhibitory Concentration (NIC)}

Penicillic acid (5) was purchased from Sigma-Aldrich, Rehovot, Israel. Non-inhibitory concentration (NIC) for plakofuranolactone (1) and penicillic acid (5) was determined by the broth two-fold micro dilution method [35]. Briefly, the compounds were dissolved in methanol to obtain $10 \mathrm{mM}$ stock solutions, which were subsequently serially diluted using Muller-Hinton broth. The inoculum (approximately $5 \times 10^{5} \mathrm{CFU} / \mathrm{mL}$, final concentration) was prepared from an overnight culture and was added $(50 \mu \mathrm{L})$ to each well containing the compound $(200 \mu \mathrm{L})$ to give a concentration range of $800-0.781 \mu \mathrm{M}$. After incubating 96-well flat bottomed plates aerobically at $37.8^{\circ} \mathrm{C}$ for $24 \mathrm{~h}$, the OD (optical density) was measured using a spectrophotometer $(600 \mathrm{~nm})$ using a TriStarMultimode Microplate reader (Berthold Technologies GmbH \& Co. KG, Bad Wildbad, Germany) to determine NIC values. In addition, the OD was measured at regular intervals during the growth, and growth curves were built from the resulting values. Negative controls (culture + methanol) were included. 


\subsection{Dose Dependent QQ Assay}

Well diffusion QQ assay was performed using C. violaceum CV026 following a pre-established protocol [36], whereas bioluminescence based QQ assay using E. coli pSB401 and E. coli pSB1075 reporters were quantified on a TriStar Multimode Microplate reader (Berthold Technologies GmbH \& Co. KG) as reported [37]. Plasmid pSB401 was constructed using the P. luminescens luxCDABE operon controlled by the PluxI gene promoter together with the $V$. fischeri luxR DNA fragment and when transformed in E. coli it emits luminescence in response to the exogenous addition of AHLs with medium $\left(\mathrm{C}_{6}-\mathrm{C}_{8}\right)$ acyl side chain lengths [37]. LasR-based reporter plasmid pSB1075 contains the lasR gene, and the promoter of $\operatorname{lasI}^{-}$controls the expression for the reporter operon luxCDABE and emits luminescence in response to AHLs with long $\left(\geq \mathrm{C}_{10}\right)$ acyl side chains [37]. Briefly, the stock solutions $(10 \mathrm{mM})$ of compounds $\mathbf{1}$ and $\mathbf{5}$ were serially diluted to NIC concentrations $(0.781-200 \mu \mathrm{M})$ in Luria-Bertani (LB) medium. The inocula of the reporter strains $\left(\mathrm{OD}_{600} 0.01\right.$, final concentration) were prepared from an overnight culture and added $(50 \mu \mathrm{L})$ to each well. The inoculum was supplemented with $\mathrm{N}$-(3-oxo-hexanoyl)-L-homoserine lactone (3-oxo-C6-HSL, $1 \mu \mathrm{M}$ final concentration) and $\mathrm{N}$-(3-oxo-dodecanoyl)-L-homoserine lactone (3-oxo-C12-HSL, $2 \mu \mathrm{M}$ final concentration) in order to stimulate QS of the pSB401 and pSB1075 biosensors, respectively. The bioluminescence was recorded every $30 \mathrm{~min}$ for $7 \mathrm{~h}$ at $30^{\circ} \mathrm{C}$. The production of bioluminescence in the graphs is given as the relative light units (RLU), obtained at $4 \mathrm{~h}$.

\subsection{Inhibition of Virulence Factor Production-Pyocyanin and Protease}

Inhibitory activity of pyocyanin production by Pseudomonas aeruginosa PAO1 was performed as described earlier [38]. Briefly, an overnight culture of $P$. aeruginosa PAO1 was diluted with LB medium to an $\mathrm{OD}_{600}$ of 0.2 and $4.5 \mathrm{~mL}$ were transferred to a $20 \mathrm{~mL}$ test tube. The diluted cultures were supplemented with $250 \mu \mathrm{L}$ of test compounds plakofuranolactone (1) or penicillic acid (5). Methanol (solvent in which test compounds were dissolved) was used for negative controls. After overnight incubation at $37^{\circ} \mathrm{C}$ and $200 \mathrm{rpm}, 3 \mathrm{~mL}$ of chloroform was added to each test tube and mixed vigorously. The organic layer was collected by centrifugation $(2000 \mathrm{~g})$ and transferred to a fresh tube. Hydrochloric acid $(0.2 \mathrm{M}, 1 \mathrm{~mL})$ was added to the organic layer and the absorbance was measured at $520 \mathrm{~nm}$. The experiments were performed in triplicate. Pyocyanin concentration $(\mu \mathrm{L} / \mathrm{mL})$ was calculated as:

$$
\mathrm{P}=(\mathrm{OD} \times 17.072) \times 1.5
$$

where OD is optical density value obtained at $520 \mathrm{~nm}, 17.072$ is the extinction coefficient used to obtain the value in $\mu \mathrm{g} / \mathrm{mL}$, and 1.5 is the dilution factor $(3 \mathrm{~mL}$ from initial $4.5 \mathrm{~mL}$ of chloroform was used) [39].

Proteolytic activity was determined using the azocasein assay as previously described [40]. Briefly, we treated wild type P. aeruginosa PAO1 strains with test compounds $\mathbf{1}$ and $\mathbf{5}$ in a dose dependent manner at NIC concentration. An overnight inoculum (approximately $5 \times 10^{5} \mathrm{CFU} / \mathrm{mL}$, final concentration) was prepared and was added to each well containing test compounds 1 or 5 $(0.781-200 \mu \mathrm{M})$ and was incubated at $37^{\circ} \mathrm{C}$ for $16 \mathrm{~h}$. Once the $\mathrm{OD}_{600}$ reached 0.4 , the plate was centrifuged and $30 \mu \mathrm{L}$ of supernatant was transferred to a clean Eppendoff tube containing $50 \mu \mathrm{L}$ of $0.8 \%$ azocasein. The mixture was incubated at $37^{\circ} \mathrm{C}$ for $12 \mathrm{~h}$. Subsequently, the mixture was incubated at room temperature for 15 min with $240 \mu \mathrm{L}$ of $10 \%(w / v)$ trichloroacetic acid (TCA), and centrifuged for $10 \mathrm{~min}$ at $15,000 \times \mathrm{g}$. Prior to spectroscopic measurement at $\mathrm{OD}_{440}, 240 \mu \mathrm{L}$ of $1 \mathrm{M} \mathrm{NaOH}$ was added. P. aeruginosa PAO1 without any treatment in diluting solvent (methanol and sterile culture media) was used as the negative control. 


\subsection{Statistical Analysis}

The significance differences between the mean values of tested subjects from their corresponding controls were tested using ANOVA Dunnett's test $(p<0.05)$ using GraphPad Prism software version 5.01. All the assays were performed in duplicates.

\section{Conclusions}

Quorum quenching, a novel approach which is based on the inhibition of the QS systems that regulate cell-cell communication and the production of virulence factors in bacteria, is now regarded as a potential therapeutic strategy to design novel drugs that will reduce virulence factors while not acting as bactericidals. However, it should be noted that the potential for the emergence of pathogen resistance against antivirulence drugs is still under debate [41-43].

A novel $\gamma$-lactone, plakofuranolactone (1), which shows a strong QQ activity at submicromolar concentration, has been discovered from the extract of the Indonesian sponge Plakortis cf. lita. The QQ activity of compound $\mathbf{1}$ was demonstrated using a biosensor, the QS-reporter strain pSB1075, in which a reporter gene (bioluminescence) is under control of the LasI/R system. The experiments showed that compound 1 can effectively inhibit AHL-induced bioluminescence. In addition, in an experiment on a wild-type strain of $P$. aeruginosa, the total protease activity (one of the virulence factors of $P$. aeruginosa which is under control of the LasI/R system) was decreased by treatment with compound 1. Therefore, plakofuranolactone can be regarded as a model scaffold to design a first generation of antivirulence drugs. The lack of QQ activity against short-chain AHL-QS systems (based on the results with biosensors C. violaceum CV026 and E. coli pSB401) suggests that the QQ activity of compound $\mathbf{1}$ is not general, but rather specific to certain QS systems. Furthermore, it supports the fact that the reduction in bioluminescence observed when compound $\mathbf{1}$ was added in the pSB1075 assay was a result of QQ and not a direct inhibition of bioluminescence, given that pSB401 is also a bioluminescence-based biosensor.

In a study on cellular localization of secondary metabolites in a Plakortis sponge [44], it has been shown that all the secondary metabolites found in the extract of the sponge are mainly or exclusively present in the bacterial fraction, and are therefore of likely microbial origin. It is even more likely that plakofuranolactone (1), a metabolite that is involved in bacterial cell-to-cell communication, is a product of bacterial metabolism, although no positive evidence is presently available in this respect. Further studies to discover the biosynthetic genes for plakofuranolactone and identify their host organism are in progress.

Supplementary Materials: The following are available online at www.mdpi.com/1660-3397/15/3/59/s1. Table S1: Calculated optical rotations for individual conformers of 1, Figure S1: ${ }^{1} \mathrm{H}-\mathrm{NMR}$ spectrum of compound 1 $\left(700 \mathrm{MHz}, \mathrm{CD}_{3} \mathrm{OD}\right)$, Figure S2: Expansion of the ${ }^{1} \mathrm{H}-\mathrm{NMR}$ spectrum of compound 1, Figure S3: COSY spectrum of compound 1, Figure S4: NOESY spectrum of compound 1, Figure S5: HSQC spectrum of compound 1, Figure S6: HMBC spectrum of compound 1, Figure S7: Growth curve inhibition profile of plakofuranolactone (1) against Pseudomonas aeruginosa PAO1, E. coli pSB401 and E. coli pSB1075, Figure S8: Effects of compounds 1 and $\mathbf{5}$ on C. violaceum CV026.

Acknowledgments: This work was funded by the European Union's Seventh Framework Programme (FP7) 2007-2013 under Grant Agreement No. 311848 (Bluegenics) and by the Università di Napoli Federico II under the STAR project (SeaLEADS). This study was partially supported by the Bi-lateral Italy-Israel R\&D grant, MOST grant\#10705-3 to LS entitled: "A novel approach to fight antibiotic-resistant pathogens: acquisition of quorum sensing inhibitors from marine sponges" (by the Ministry of Science and Technology, Israel). K.S. had a post-doctoral fellowship from the Israeli Council for Higher Education (VATAT) and University of Haifa.

Author Contributions: V.C. and L.S. conceived and designed the experiments; R.T., K.S. and R.B.-S. performed the experiments; V.C., L.S., R.T., K.S. and A.M. analyzed the data; V.C., A.M., G.D.S., K.S. and L.S. wrote the paper. Conflicts of Interest: The authors declare no conflict of interest. 


\section{References}

1. Coates, A.R.; Halls, G.; Hu, Y. Novel classes of antibiotics or more of the same? Br. J. Pharmacol. 2011, 163, 184-194. [CrossRef] [PubMed]

2. Blunt, J.W.; Copp, B.R.; Keyzers, R.A.; Munro, M.H.G.; Prinsep, M.R. Marine natural products. Nat. Prod. Rep. 2016, 33, 382-431. [CrossRef] [PubMed]

3. Esposito, G.; Teta, R.; Miceli, R.; Ceccarelli, L.S.; Della Sala, G.; Camerlingo, R.; Irollo, E.; Mangoni, A.; Pirozzi, G.; Costantino, V. Isolation and Assessment of the in Vitro Anti-Tumor Activity of Smenothiazole A and B, Chlorinated Thiazole-Containing Peptide/Polyketides from the Caribbean Sponge, Smenospongia aurea. Mar. Drugs 2015, 13, 444-459. [CrossRef] [PubMed]

4. Costantino, V.; Fattorusso, E.; Mangoni, A.; Perinu, C.; Cirino, G.; De Gruttola, L.; Roviezzo, F. Tedanol: A potent anti-inflammatory ent-pimaranediterpene from the Caribbean Sponge Tedania ignis. Bioorg. Med. Chem. 2009, 17, 7542-7547. [CrossRef] [PubMed]

5. Costantino, V.; D’Esposito, M.; Fattorusso, E.; Mangoni, A.; Basilico, N.; Parapini, S.; Taramelli, D. Damicoside from Axinella damicornis: The influence of a glycosylated galactose 4-OH group on the immunostimulatory activity of $\alpha$-galactoglycolsphingolipids. J. Med. Chem. 2005, 48, 7411-7417. [CrossRef] [PubMed]

6. Costantino, V.; Fattorusso, E.; Imperatore, C.; Mangoni, A.; Freigang, S.; Teyton, L. Glycolipids from Sponges. 18. Corrugoside, a New Immunostimulatory alpha-Galactoglycosphingolipid from the Marine Sponge Axinella corrugata. Bioorg. Med. Chem. 2008, 16, 2077-2085. [CrossRef] [PubMed]

7. Laport, M.S.; Santos, O.C.; Muricy, G. Marine sponges: Potential sources of new antimicrobial drugs. Curr. Pharm. Biotechnol. 2009, 10, 86-105. [CrossRef] [PubMed]

8. Mayer, A.M.; Rodríguez, A.D.; Taglialatela-Scafati, O.; Fusetani, N. Marine pharmacology in 2009-2011: Marine compounds with antibacterial, antidiabetic, antifungal, anti-inflammatory, antiprotozoal, antituberculosis, and antiviral activities; affecting the immune and nervous systems, and other miscellaneous mechanisms of action. Mar. Drugs 2013, 11, 2510-2573. [PubMed]

9. Fuqua, C.; Parsek, M.R.; Greenberg, E.P. Regulation of gene expression by cell-to-cell communication: Acyl-homoserine lactone quorum sensing. Annu. Rev. Genet. 2001, 35, 439-468. [CrossRef] [PubMed]

10. Schuster, M.; Lostroh, C.P.; Ogi, T.; Greenberg, E.P. Identification, timing, and signal specificity of Pseudomonas aeruginosa quorum-controlled genes: A transcriptome analysis. J. Bacteriol. 2003, 185, 2066-2079. [CrossRef] [PubMed]

11. Wagner, V.E.; Bushnell, D.; Passador, L.; Brooks, A.I.; Iglewski, B.H. Microarray analysis of Pseudomonas aeruginosa quorum-sensing regulons: Effects of growth phase and environment. J. Bacteriol. 2003, 185, 2080-2095. [CrossRef] [PubMed]

12. Passador, L.; Cook, J.M.; Gambello, M.J.; Rust, L.; Iglewski, B.H. Expression of Pseudomonas aeruginosa virulence genes requires cell-to-cell communication. Science 1993, 260, 1127-1130. [CrossRef] [PubMed]

13. Winson, M.K.; Camara, M.; Latifi, A.; Foglino, M.; Chhabra, S.R.; Daykin, M.; Bally, M.; Chapon, V.; Salmond, G.P.; Bycroft, B.W. Multiple N-acyl-L-homoserine lactone signal molecules regulate production of virulence determinants and secondary metabolites in Pseudomonas aeruginosa. Proc. Natl. Acad. Sci. USA 1995, 92, 9427-9431. [CrossRef] [PubMed]

14. Van Delden, C.; Iglewski, B.H. Cell-to-cell signaling and Pseudomonas aeruginosa infections. Emerg. Infect. Dis. 1998, 4, 551-560. [CrossRef] [PubMed]

15. Hentzer, M.; Givskov, M. Pharmacological inhibition of quorum sensing for the treatment of chronic bacterial infections. J. Clin. Investig. 2003, 112, 1300-1307. [CrossRef] [PubMed]

16. Saurav, K.; Bar-Shalom, R.; Haber, M.; Burgsdorf, I.; Oliviero, G.; Costantino, V.; Morgenstern, D.; Steindler, L. In Search of Alternative Antibiotic Drugs: Quorum-Quenching Activity in Sponges and their Bacterial Isolates. Front. Microbiol. 2016, 7, 416. [CrossRef] [PubMed]

17. Kindersoe, M.E.; Ettinger-Epstein, P.; Rasmussen, T.B.; Bjarnsholt, T.; de Nys, R.; Givskov, M. Quorum sensing antagonism from marine organisms. Mar. Biotechnol. 2008, 10, 56-63. [CrossRef] [PubMed]

18. Skindersoe, M.; de Nys, R.; Kumar, N.; Read, R.; Givskov, M.; Steinberg, P.; Kjelleberg, S. Evidence that halogenated furanones from Deliseapulchra inhibit acylated homoserine lactone (AHL)-mediated gene expression by displacing the AHL signal from its receptor protein. Microbiology 1999, 145, 283-291. 
19. Cafieri, F.; Fattorusso, E.; Taglialatela-Scafati, O.; Di Rosa, M.; Ianaro, A. Metabolites from the sponge Plakortis simplex. Isolation of four bioactive lactone compounds and of a novel related amino acid. Tetrahedron 1999, 55, 13831-13840. [CrossRef]

20. Gunasekera, S.P.; Isbrucker, R.A.; Longley, R.E.; Wright, A.E.; Pomponi, S.A.; Reed, J.K. Plakolide A, a New $\gamma$-Lactone from the Marine Sponge Plakortis sp. J. Nat. Prod. 2004, 67, 110-111. [CrossRef] [PubMed]

21. De Guzman, F.S.; Schimitz, F.J. Peroxy aliphatic esters from the sponge Plakortis lita. J. Nat. Prod. 1990, 53, 926-931. [CrossRef]

22. Costantino, V.; Della Sala, G.; Mangoni, A.; Perinu, C.; Teta, R. Blurring the Boundary between Bio- and Geohopanoids: Plakohopanoid, a C32 Biohopanoid Ester from Plakortis cf. lita. Eur. J. Org. Chem. 2012, 2012, 5171-5176. [CrossRef]

23. Quinoa, E.; Kho, E.; Manes, L.V.; Crews, P.; Bakus, G.J. Heterocycles from the marine sponge Xestospongia sp. J. Org. Chem. 1986, 51, 4260-4264. [CrossRef]

24. Haghdani, S.; Gautun, O.R.; Koch, H.; Åstrand, P.O. Optical Rotation Calculations for a Set of Pyrrole Compounds. J. Phys. Chem. A 2016, 120, 7351-7360. [CrossRef] [PubMed]

25. Frisch, M.J.; Trucks, G.W.; Schlegel, H.B.; Scuseria, G.E.; Robb, M.A.; Cheeseman, J.R.; Scalmani, G.; Barone, V.; Mennucci, B.; Petersson, G.A.; et al. Gaussian 09; Revision E. 01; Gaussian, Inc.: Wallingford, CT, USA, 2009.

26. Rasmussen, B.T.; Skindersoe, E.M.; Jarnsholt, B.T.; Phipps, K.R.; Christensen, B.K.; Jensen, P.O.; Andersen, J.B.; Koch, B.; Larsen, T.O.; Hentzer, M.; et al. Identity and effects of quorum-sensing inhibitors produced by Penicillium species. Microbiology 2005, 151, 1325-1340. [CrossRef] [PubMed]

27. Skindersoe, M.E.; Alhede, M.; Phipps, R.; Yang, L.; Jensen, P.O.; Rasmussen, T.B. Effects of Antibiotics on Quorum Sensing in Pseudomonas aeruginosa. Antimicrob. Agents Chemother. 2008, 52, 3648-3663. [CrossRef] [PubMed]

28. Tan, S.Y.Y.; Chua, S.-L.; Chen, Y.; Rice, S.A.; Kjelleberg, S.; Nielsen, T.E.; Yang, L.; Givskov, M. Identification of Five Structurally Unrelated Quorum-Sensing Inhibitors of Pseudomonas aeruginosa from a Natural-Derivative Database. Antimicrob. Agents Chemother. 2013, 57, 5629-5641. [CrossRef] [PubMed]

29. Kwan, J.C.; Teplitski, M.; Gunasekera, S.P.; Paul, V.J.; Luesch, H. Isolation and biological evaluation of 8-epi-malyngamide $C$ from the Floridian marine cyanobacterium Lyngbya majuscula. J. Nat. Prod. 2010, 73, 463-466. [CrossRef] [PubMed]

30. Dobretsov, S.; Teplitski, M.; Alagely, A.; Gunasekera, S.P.; Paul, V.J. Malyngolide from the cyanobacterium Lyngbya majuscula interferes with quorum sensing circuitry. Environ. Microbiol. Rep. 2010, 2, 739-744. [CrossRef] [PubMed]

31. Kwan, J.C.; Meickle, T.; Ladwa, D.; Teplitski, M.; Paul, V.; Luesch, H. Lyngbyoic acid, a "tagged" fatty acid from a marine cyanobacterium, disrupts quorum sensing in Pseudomonas aeruginosa. Mol. Biosyst. 2011, 7, 1205-1216. [CrossRef] [PubMed]

32. Chan, K.-G.; Liu, Y.-C.; Chang, C.-Y. Inhibiting N-acyl-homoserine lactone synthesis and quenching Pseudomonas quinolone quorum sensing to attenuate virulence. Front. Microbiol. 2015, 6, 1173. [CrossRef] [PubMed]

33. Moore, J.D.; Joseph, P.; Gerdt, J.P.; Nora, R.; Eibergen, N.R.; Blackwell, H.E. Active efflux influences the potency of quorum sensing inhibitors in Pseudomonas aeruginosa. ChemBioChem 2014, 15, 435-442. [CrossRef] [PubMed]

34. Welsh, M.A.; Helen, E.; Blackwell, H.E. Chemical probes of quorum sensing: From compound development to biological discovery. FEMS Microbiol. Rev. 2016, 40, 774-794. [CrossRef] [PubMed]

35. Clinical and Laboratory Standards Institute. CLSI Document M100S17. Performance Standards for Antimicrobial Susceptibility Testing, 17th Informational Supplement; Clinical and Laboratory Standards Institute: Wayne, PA, USA, 2007.

36. McClean, K.H.; Winson, M.K.; Fish, L.; Taylor, A.; Chhabra, S.R.; Camara, M.; Daykin, M.; Lamb, J.H.; Swift, S.; Bycroft, B.W.; et al. Quorum sensing and Chromobacterium violaceum: Exploitation of violacein production and inhibition for the detection of $N$-acylhomoserine lactones. Microbiology 1997, 143, 3703-3711. [CrossRef] [PubMed]

37. Winson, M.K.; Swift, S.; Fish, L.; Throup, J.P.; Jørgensen, F.; Chhabra, S.R.; Bycroft, B.W.; Williams, P.; Stewart, G.S. Construction and analysis of luxCDABE-based plasmid sensors for investigating $N$-acyl homoserine lactone-mediated quorum sensing. FEMS Microbiol Lett. 1998, 163, 185-192. [CrossRef] [PubMed] 
38. Pejin, B.; Talevska, A.; Ciric, A.; Glamoclija, J.; Nikolic, M.; Talevski, T.; Sokovic, M. Anti-quorum sensing activity of selected sponge extracts: A case study of Pseudomonas aeruginosa. Nat. Prod. Res. 2014, 28, 2330-2333. [CrossRef] [PubMed]

39. El-Foulya, M.Z.; Sharafb, A.M.; Shahina, A.A.M.; El-Bialya, H.A.; Omara, A.M.A. Biosynthesis of pyocyanin pigment by Pseudomonas aeruginosa. J. Radiat. Res. Appl. Sci. 2015, 8, 36-48. [CrossRef]

40. Christensen, A.B.; Riedel, K.; Eberl, L.; Flodgaard, L.R.; Molin, S.; Gram, L.; Givskov, M. Quorum-sensingdirected protein expression in Serratia proteamaculans B5a. Microbiology 2003, 149, 471-483. [CrossRef] [PubMed]

41. Defoirdt, T.; Boon, N.; Bossier, P. Can bacteria evolve resistance to quorum sensing disruption? PLoS Pathog. 2010, 6, e1000989. [CrossRef] [PubMed]

42. Allen, R.C.; Popat, R.; Diggle, S.P.; Brown, S.P. Targeting virulence: Can we make evolution-proof drugs? Nat. Rev. Microbiol. 2014, 12, 300-308. [CrossRef] [PubMed]

43. García-Contreras, R.; Maeda, T.; Wood, T.K. Resistance to Quorum-Quenching Compounds. Appl. Environ. Microbiol. 2013, 79, 6840-6846. [CrossRef] [PubMed]

44. Laroche, M.; Imperatore, C.; Grozdanov, L.; Costantino, V.; Mangoni, A.; Hentschel, U.; Fattorusso, E. Cellular localisation of secondary metabolites isolated from the Caribbean sponge Plakortis simplex. Mar. Biol. 2007, 151, 1365-1373. [CrossRef]

(C) 2017 by the authors. Licensee MDPI, Basel, Switzerland. This article is an open access article distributed under the terms and conditions of the Creative Commons Attribution (CC BY) license (http:/ / creativecommons.org/licenses/by/4.0/). 